\title{
Ilaria Biondi, Il Viaggio a Maiorca di George Sand. Fra esplorazione del luogo ed esplorazione del sé, in «Ottocento»
}

\section{Marco Stupazzoni}

\section{(2) OpenEdition}

\section{Journals}

\section{Edizione digitale}

URL: http://journals.openedition.org/studifrancesi/7645

DOI: $10.4000 /$ studifrancesi.7645

ISSN: 2421-5856

\section{Editore}

Rosenberg \& Sellier

\section{Edizione cartacea}

Data di pubblicazione: 1 décembre 2009

Paginazione: 650-651

ISSN: 0039-2944

\section{Notizia bibliografica digitale}

Marco Stupazzoni, «llaria Biondi, Il Viaggio a Maiorca di George Sand. Fra esplorazione del luogo ed esplorazione del sé, in "Ottocento»», Studi Francesi [Online], 159 (LIII | III) | 2009, online dal 30 novembre 2015, consultato il 09 janvier 2021. URL: http://journals.openedition.org/studifrancesi/7645 ; DOI: https://doi.org/10.4000/studifrancesi.7645

Questo documento è stato generato automaticamente il 9 janvier 2021.

\section{cc) (†) $\odot$}

Studi Francesi è distribuita con Licenza Creative Commons Attribuzione - Non commerciale - Non opere derivate 4.0 Internazionale. 


\title{
Ilaria Biondi, Il Viaggio a Maiorca di George Sand. Fra esplorazione del luogo ed esplorazione del sé, in «Ottocento»
}

\author{
Marco Stupazzoni
}

\section{NOTIZIA}

ILARIA BIONDI, Il Viaggio a Maiorca di George Sand. Fra esplorazione del luogo ed esplorazione del sé, in «Ottocento», anno VII, nº 16, settembre-ottobre 2008, pp. 53-55.

1 In questa breve nota, l'autore si sofferma sui ricordi del viaggio compiuto nel 1838 da George Sand a Maiorca in compagnia di Frédéric Chopin offrendo una rilettura di Un Hiver à Majorque, un'opera che, a suo giudizio, è suscettibile di una duplice interpretazione: anzitutto come racconto di viaggio e, allo stesso tempo, come «resoconto di un'importante esperienza esistenziale». Tutt'altro che insensibile al paesaggio naturale dell'isola, la scrittrice vive questo soggiorno nell'isola come momento mitico e immaginario, come «cruciale punto d'incontro tra il finito e l'immensità» (p.54), ossia come luogo di una esperienza interiore e di una profonda presa di coscienza dell'Io. 